Bulletin of Pharmaceutical Sciences
Assiut University
Website: http://bpsa.journals.ekb.eg/
e-mail: bullpharm@aun.edu.eg

\title{
ARISTOLOCHIC ACID I DETERMINATION IN ARISTOLOCHIA CLEMATITIS L. RAW MATERIALS BY HPLC METHOD
}

\author{
Lala Pohodina ${ }^{1}$, Nadiia Burda ${ }^{1 *}$, Viktoriia Kyslychenko ${ }^{1}$, Larisa Andryukova ${ }^{2}$ and \\ Artur Martynov ${ }^{3}$ \\ ${ }^{1}$ Department of Chemistry of Natural Compounds and Nutritiology, National University of \\ Pharmacy, Kharkiv, Ukraine \\ ${ }^{2}$ Department of Industrial Pharmacy and Economics, National University of Pharmacy, \\ Kharkiv, Ukraine \\ ${ }^{3}$ Mechnikov Institute of Microbiology and Immunology, National Academy of Medical Sciences \\ of Ukraine, Kharkiv, Ukraine
}

\begin{abstract}
Aristolochia clematitis has long ago been applied in Asian traditional medicine and demonstrates multidirectional pharmacological activity. Contemporary research has confirmed its expressed antimicrobial activity.

Using high performance liquid chromatography (HPLC) we ascertained and determined the content of aristolochic acid 1 in herb and roots of Aristolochia clematitis collected within the blooming period in Kharkiv and Khmelnytskyi Regions, Ukraine. As aristolochic acid I causes nephrotoxic activity of plants, particularly, Aristolochia clematitis, it is quite mandatory to control its content in raw materials. The content of aristolochic acid I in Aristolochia clematitis herb was $0.11 \pm 0.01 \%$, in roots its content was $0.14 \pm 0.01 \%$. Thus, issuing from the results of our experiment, we concluded that Aristolochia clematitis raw materials may be treated as feasible for the development of drugs, but only for external application. The results of our study may be used for the development of Aristolochia clematitis raw materials standardization parameters and safe application.
\end{abstract}

\section{INTRODUCTION}

Aristolochia genus is one of the most numerous in Aristolochiaceae family and embraces near 500 herbaceous perennial species, many of them are creepers. This species is met in Asia, Africa, North and South America, Australia, especially in tropical Asia $^{1-3}$. The plants are used in traditional medicine and homeopathy, mainly in Asian countries (China, Bangladesh, etc.) ${ }^{1 \& 4}$. The plants serve as anti-inflammatory, diuretic means, as well as antimicrobial drug for treatment of urogenital diseases, eczema, fungus cutaneous diseases, snake bites ${ }^{1,3,5 \& 6}$.

Many researchers experimentally proved antimicrobial activity for Aristolochia genus plants: ethanol extract from Aristolochia galeata is active relative to Staphylococcus aureus $^{7}$; essential oil from Aristolochia indica shows moderately expressed antimicrobial activity, whereas aqueous and ethanol extracts from Aristolochia clematitis, herb and roots collected within the budding and blooming period were studied as regards antimicrobial activity. Antimicrobial activity was most clearly expressed in extracts from this plant collected within the blooming period, especially relative to Staphylococcus aureus and Bacillus subtilis ${ }^{8}$.

However, Aristolochia genus plants possess nephrotoxic and carcinogenic action which may refer to presence of aristolochic $\operatorname{acids}^{1,9-12}$. 
Therefore, for safe application of plants containing aristolochic acids, they must be strictly controlled as regards their content.

The most of researches devoted to study of aristolochic acids in plants, particularly, of Aristolochia genus, have been devoted to either determination of aristolochic acid I, or separation of mixture of aristolochic acid I and aristolochic acid II ${ }^{9,13-15}$.

Aristolochic acid I (synonym: aristolochic acid AA-I) is a nitrophenanthrene carboxylic acid, considered to be one of the most active substances in Aristolochia genus plants ${ }^{2}$ (Fig. $1)$.<smiles>COc1cccc2c1cc([N+](=O)[O-])c1c(C(=O)O)cc3c(c12)OCO3</smiles>

Fig. 1: Structural formula of aristolochic acid I.

In European countries, particularly in Ukraine, Aristolochia clematitis grows as a weed. This plant is not included to Pharmacopoeia, its application has certain limitations, but it is promising in some aspects, particularly as a raw material for the development of externally applied drugs.

Aristolochia clematitis raw material requires a thorough study, including determination of aristolochic acid I which is mandatory for creation of safe drugs. Its content in plant must be established and controlled.

Therefore, the present work is devoted to determination of aristolochic acid I in Aristolochia clematitis herb and roots.

\section{MATERIALS AND METHODS}

\section{Plant Materials}

Aristolochia clematitis herb and roots were collected within the blooming phase in Kharkiv and Khmelnytskyi Regions, Ukraine, in MayJune 2019/2020.

Plant samples were identified by Professor Iryna Zhuravel, Department of Chemistry of Natural Compounds and Nutritiology, National
University of Pharmacy, Ukraine. The voucher specimen was deposited at National University of Pharmacy (Ukraine) with certain number $1506 / 2019$.

\section{Research methodology and chromatography conditions}

As the State Pharmacopoeia of Ukraine (SPU) has been a member of the European Pharmacopoeia (EP) since 2013, the methods specified therein are associated with the EP requirements (except national part). According to both EP and SPU, for raw materials containing aristolochic acids their determination is mandatory.

Thus, for our research we applied SPU 2.0 Method 2.8.21 "Aristolochic acids content in herbal raw material test" $"$ " \& 17.

The chromatographic study of tested herb specimens was performed at a Shimadzu HPLC-system, ser.20 liquid chromatograph equipped with a diode matrix detector under the following conditions:

- Xterra MS C18 column, dimensions: 150 $\mathrm{mm}$ x 4,6 mm, particle size 3,5 $\mu \mathrm{m}$;

- Column temperature $40^{\circ} \mathrm{C}$;

- Detector wavelength $390 \mathrm{~nm}$;

- Mobile phase flow rate $0.3 \mathrm{ml} / \mathrm{min}$;

- Introduced sample volume $25 \mu 1$.

The mobile phase is shown in table 1.

Table 1: Mobile phase.

\begin{tabular}{|c|c|c|}
\hline $\begin{array}{c}\text { Chromatography } \\
\text { time, min }\end{array}$ & Eluent $\mathrm{A},{ }^{\mathrm{a}} \%$ & Eluent $\mathrm{B},{ }^{\mathrm{b}} \%$ \\
\hline $0-25$ & $85 \rightarrow 35$ & $15 \rightarrow 65$ \\
\hline $25-30$ & $35 \rightarrow 0$ & $65 \rightarrow 100$ \\
\hline $30-31$ & $0 \rightarrow 85$ & $100 \rightarrow 15$ \\
\hline
\end{tabular}

${ }^{a}$ Eluent A: $0.1 \%$ aqueous solution of trifluoroacetic acid.

${ }^{\mathrm{b}}$ Eluent B: $0.1 \%$ acetonitrile solution of trifluoroacetic acid.

The components were identified by their retention time and conformity of their UV spectra to standard substance.

The calculations were performed by the equation: 
$X, \%=\frac{A_{p r} \times m_{s t} \times V_{p r} \times P \times 100}{A_{s t} \times V_{s t} \times m_{p r} \times 100}$

where: $A_{p r}$ - substance peak area in tested solution chromatogram; $\mathrm{A}_{\mathrm{st}}$ - substance peak area in reference solution chromatogram; $\mathrm{m}_{\mathrm{st}}-$ mass of substance standard sample, $\mathrm{mg} ; \mathrm{m}_{\mathrm{pr}}-$ mass of tested herb sample, $\mathrm{mg} ; \mathrm{V}_{\mathrm{pr}}$ - dilution of tested solution, $\mathrm{ml} ; \mathrm{V}_{\mathrm{st}}$ - dilution of reference solution, $\mathrm{ml} ; \mathrm{P}$ - activity of standard, $\%$.

\section{Preparation of analyzed solutions}

Tested solution: $1 \mathrm{~g}$ powdered raw material was placed to a $250 \mathrm{ml}$ dark glass flask, $100 \mathrm{ml}$ solvent mixture (acetonitrilewater 50:50) was added. It was kept on ultrasonic bath for $30 \mathrm{~min}$ and filtered through $0,45 \mu \mathrm{m}$ filter.

Reference solution: $1 \mathrm{mg}$ standard aristolochic acid I sample (from ChemFaces, China, Catalog No.CFN99505) was dissolved in $5 \mathrm{ml}$ solvent mixture (acetonitrile-water 50:50). $1 \mathrm{ml}$ of obtained solution was transferred to a $10 \mathrm{ml}$ flask and diluted with a solvent mixture up to the mark. The solution was filtered through $0,45 \mu \mathrm{m}$ filter.

\section{Statistical analysis}

IBM SPSS Statistics for Windows, Version 26.0 was used for statistical analysis of results. Results are expressed as means of three measurements $\pm \mathrm{SD}$. A probability of less than 0.05 ( $p<0.05)$ was considered statistically significant.

\section{RESULTS AND DISCUSSIONS}

HPLC chromatogram of standard substance - aristolochic acid I - is shown in figure 2 .
HPLC chromatograms of aristolochic acid I determination in Aristolochia clematitis herb and roots are given in figures 3 and 4 .

Chromatographic parameters for standard substance aristolochic acid I and aristolochic acid I determination in tested raw materials are specified in table 2 .

The results of our research proved that aristolochic acid I content in Aristolochia clematitis herb (as dry matter) was $0.11 \pm 0.01 \%$, whereas its content in roots was $0.14 \pm 0.01 \%$.

Thus, aristolochic acid I dominated in subterranean part of Aristolochia clematitis.

Chinese scientists studied 31 samples of Aristolochia fangchi $W u$ raw materials collected in various regions of China and found that the content of aristolochic acids acutely varied depending on the vegetation area of a particular plant. Nevertheless, they remarked that in most cases aristolochic acid I content was much higher than that of aristolochic acid II $^{9}$.

US researchers also confirmed this trend in aristolochic acids accumulation: in most tested raw material samples characterized by the presence of these compounds aristolochic acid I dominated ${ }^{5}$.

However, the scientists from Sudan have established that Aristolochia bracteolata contained aristolochic acid I to the amount of $12.98 \mathrm{~g} / \mathrm{kg}$, whereas the content of aristolochic acid II was $49.03 \mathrm{~g} / \mathrm{kg}^{18}$.

As regards the comparison of our results with those of other researchers it may be concluded that aristolochic acid I content varies in quite wide range, beginning from traces, and this substance usually dominates among other aristolochic acids.

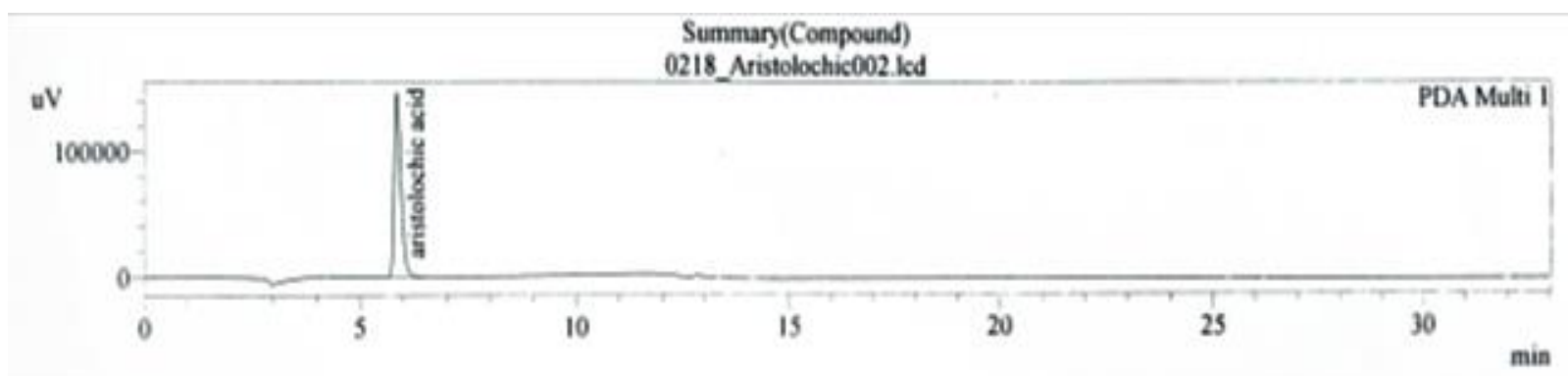

Fig. 2: HPLC chromatogram of standard substance aristolochic acid I. 


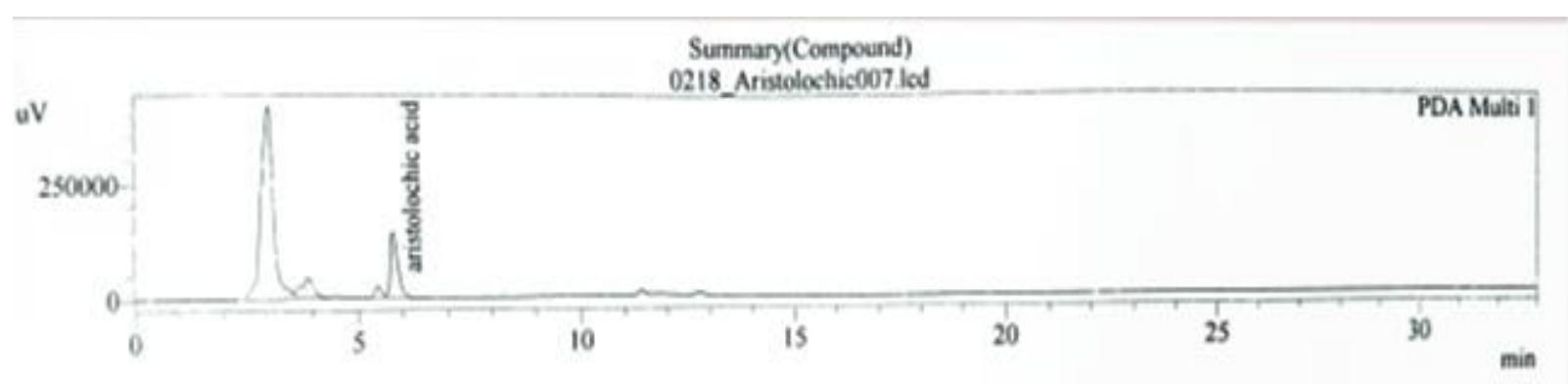

Fig. 3: HPLC chromatogram of aristolochic acid I determination in Aristolochia clematitis herb.

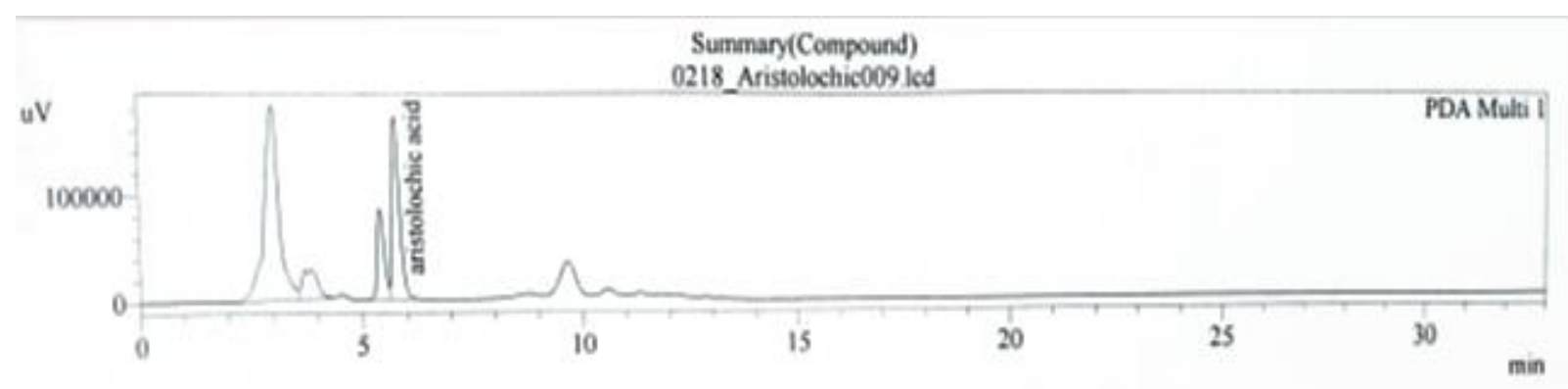

Fig. 4: HPLC chromatogram of aristolochic acid I determination in Aristolochia clematitis roots.

Table 2: Chromatographic parameters for determination of standard substance aristolochic acid I and aristolochic acid I determination in tested raw materials.

\begin{tabular}{|l|c|c|c|c|c|}
\hline \multicolumn{1}{|c|}{ Title } & $\begin{array}{c}\text { Retention } \\
\text { time }\end{array}$ & Area & Tailing factor & Theoretical plate & Resolution \\
\hline $\begin{array}{l}\text { Standard } \\
\text { substance }\end{array}$ & $5.847 \pm 0.022$ & $1616115 \pm 4249$ & $1.435 \pm 0.008$ & $6231.625 \pm 64.228$ & 0.000 \\
\hline $\begin{array}{l}\text { Aristolochia } \\
\text { clematitis herb }\end{array}$ & $5.810 \pm 0.034$ & $1604649 \pm 4653$ & $1.443 \pm 0.005$ & $5931.127 \pm 64.056$ & $1.190 \pm 0.003$ \\
\hline $\begin{array}{l}\text { Aristolochia } \\
\text { clematitis } \\
\text { roots }\end{array}$ & $5.773 \pm 0.027$ & $1934423 \pm 4836$ & $1.441 \pm 0.007$ & $5784.647 \pm 56.689$ & $1.175 \pm 0.002$ \\
\hline
\end{tabular}

\section{Conclusions}

Thus, our comparative chromatographic study established that aristolochic acid I is predominantly accumulated in roots of Aristolochia clematitis $(0.14 \pm 0.01 \%)$. The analysis of our results as well as of the results of other researchers showed that the content of aristolochic acid I varies depending on vegetation area of Aristolochia genus plants, particularly, Aristolochia clematitis.

Besides, issuing from the previous research, we may conclude that Aristolochia clematitis raw material is feasible for the development of drugs, predominantly for external application.

Control of aristolochic acid I content in Aristolochia clematitis herb and roots is mandatory under the development of standardization parameters for this raw material. Therefore, the obtained results may be used for standardization of Aristolochia clematitis raw materials as well as for the development of novel drug preparations on the basis of Aristolochia clematitis herb and roots. 


\section{Acknowledgement}

This research did not receive any specific grant from funding agencies in the public, commercial, or not-forprofit sectors.

The authors declare no conflict of interest, financial or otherwise.

\section{REFERENCES}

1- J. C. Holzbach, I. R. Nascimento and L. M. X. Lopes, "Phenylethylpyranone and aristolochic acid derivatives from Aristolochia urupaensis", J. Braz. Chem. Soc., 28 (11), 2275-2279 (2017).

2- P.-C. Kuo, Y.-C. Li and T.-S. Wu, "Chemical constituents and pharmacology of the Aristolochia (馬兒鈴 mădōu ling) species", J. Tradit. Complement. Med., 2 (4), 249-266 (2012).

3- S. Latha, P. Selvamani, P. S. Dhivya and R. Benaseer Begam, "A review on pharmacological activities of Aristolochia species", EJBPS, 2 (5), 160-167 (2015).

4- T.-S. Wu, A. G. Damu, C.-R. Su and P.-C. Kuo, "Terpenoids of Aristolochia and their biological activities", Nat. Prod. Rep., 21 (5), 594-624 (2004).

5- L. Vaclavik, A. J. Krynitsky and J. I. Rader, "Quantification of aristolochic acids I and II in herbal dietary supplements by ultra-high-performance liquid chromatography - multistage fragmentation mass spectrometry", Food Additives \& Contaminants: Part A, 31 (5), 784-791 (2014).

6- H. Sati, B. Sati, S. Saklani, P. C. Bhatt and A. P. Mishra, "Phytochemical and pharmacological potential of Aristolochia indica: A review", RJPBCS, 2 (4), 647654 (2011).

7- Á. A. Aleixo, V. N. Camargos, A. C. d. S. Pereira Andrade, K. M. S. Herrera, R. I. M. d. A. Ribeiro, K. Monteiro dos Santos, J. Teixeira de Magalhães, J. C. Magalhães, L. A. Rodrigues dos Santos Lima and J. M. S. Ferreira, "Antibacterial and cytotoxic antibacterial potential of ethanol extract and fractions from Aristolochia galeata Mart. ex Zucc.", J. Med. Plant Res., 8 (6), 326-330 (2014).
8- L. I. Pohodina, V. S. Kyslychenko and N. Ye. Burda, Patent No 141876 (Ukraine), "Herbal Origin Antimicrobial Drug", applied 20.11.2019; published 27.04.2020, Bulletin No 8/2020. (in Ukrainian).

9- W. Li, R. Li, T. Bo, H. Liu, X. Feng and $\mathrm{S}$. $\mathrm{Hu}$, "Rapid determination of aristolochic acids I and II in some medicinal plants by highperformance liquid chromatography", Chromatographia, 59, 233-236 (2004).

10- J. Michl, H. M. Jennings, G. C. Kite, M. J. Ingrouille, M. S. J. Simmonds and M. Heinrich, "Is aristolochic acid nephropathy a widespread problem in developing countries?: A case study of Aristolochia indica L. in Bangladesh using an ethnobotanical - phytochemical approach", J. Ethnopharmacol., 149 (1), 235-244 (2013).

11- "IARC Monographs on the Evaluation of Carcinogenic Risks to Humans, No. 100 A", Lyon (FR), International Agency for Research on Cancer, 2012, p. 463.

12- G. B. Fogazzi and C. Bellincioni, "Aristolochia clematitis, the herb responsible for aristolochic acid nephropathy, in an uncultivated piece of land of an Italian nephrologist", Nephrol. Dial. Transpl., 30 (11), 1893-1896 (2015).

13- J.-R. Ioset, G. Raoelison and K. Hostettmann, "An LC/DAD-UV/MS method for the rapid detection of aristolochic acid in plant preparations", Planta Med., 68 (9), 856-858 (2002).

14- F. Kvasnička, R. Ševčík, M. Voldřich and J. Krátká, "Determination of aristolochic acid by capillary zone electrophoresis", CEJC, 2 (3), 417-424 (2004).

15- G. C. Kite, M. A. Yule, C. Leon and M. S. J. Simmonds, "Detecting aristolochic acids in herbal remedies by liquid chromato-graphy / serial mass spectrometry", Rapid Commun. Mass Spectrom., 16 (6), 585-590 (2002).

16- "State Pharmacopoeia of Ukraine", in 3 vols, State Enterprise Ukrainian Research Pharmacopoeia Center of Drugs Quality, $2^{\text {nd }}$ Edn., Vol. 1, Kharkiv, State Enterprise Ukrainian Research Pharmacopoeia 
Center of Drugs Quality, 2015, p.1128 (in Ukrainian).

17- M. Araya, S. García and M. GonzálezTeuber, "Rapid identification and simultaneous quantification of aristolochic acids by HPLC-DAD and confirmations by MS in Aristolochia chilensis using a limited biomass", Journal of Analytical Methods in Chemistry, 2018, 1-8 (2018).
18- A. A. Abdelgadir, E. M. Ahmed and M. S. Eltohami, "Isolation, characterization and quantity determination of aristolochic acids, toxic compounds in Aristolochia bracteolata L.", Environmental Health Insights, 5, 1-8 (2011). 


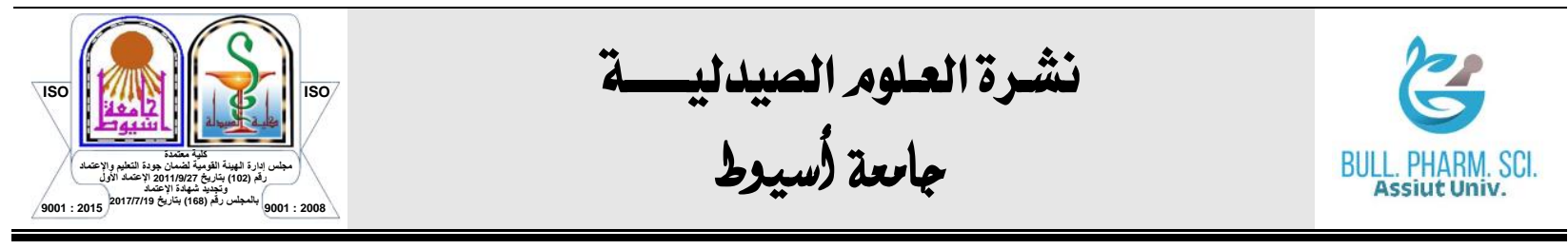

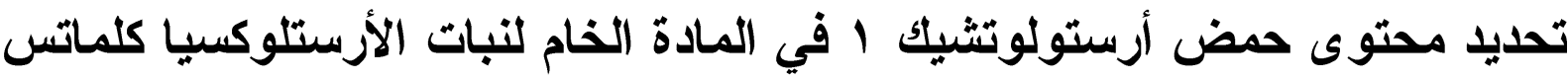
باستخدام الكروماتوجر (فيا السائلة عالية الأداء (HPLC)

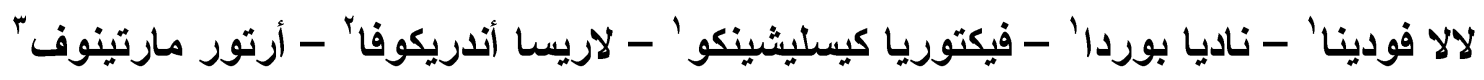

' قسم كيمياء النواتج الطبيعية و علم التغذية ، الجامعة الوطنية للصيدلة ، خاركيف ، أوكرانيا

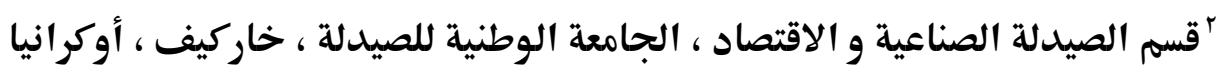

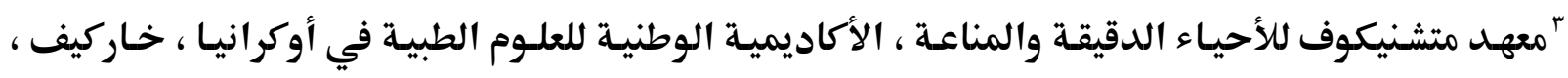
أوكرانيا

لطالما تم استخدام نبات الأرستلوكسيا كلماتس في الطب التقليدي الآسيوي وأظهر نشاطها دو ائيًا

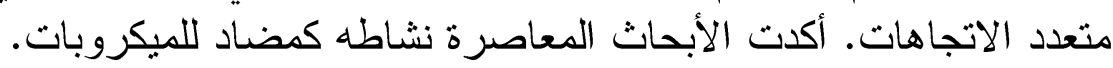

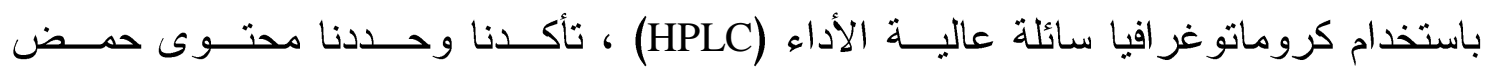

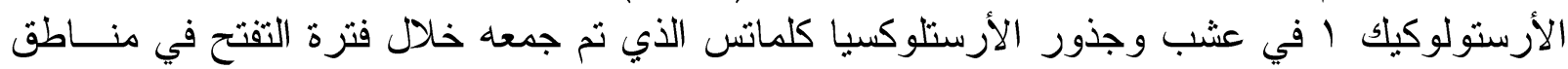

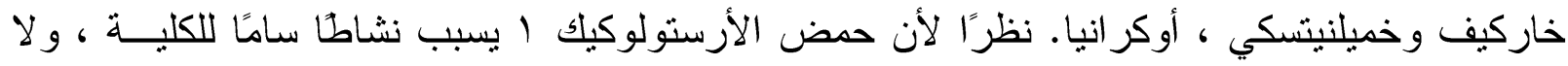

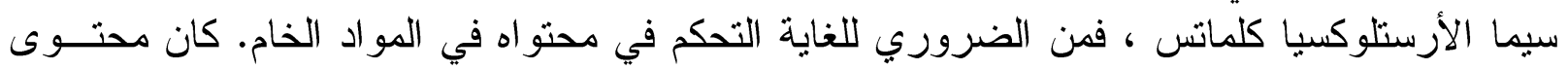

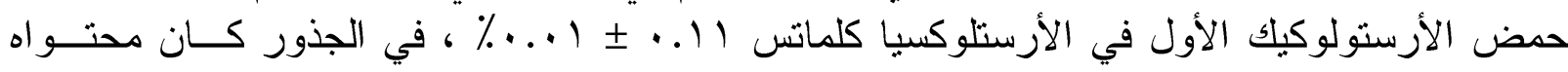
ع ا..

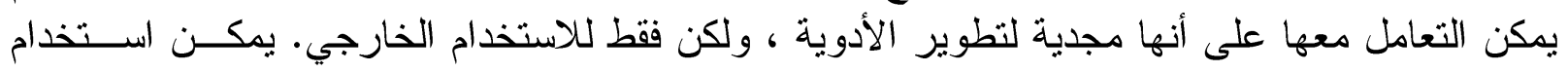
نتائج در استتا في تطوير معايير الرقابة لنبات الأرستلوكسيا كلماتس و الاستخدام الآمن لله. 